\title{
Wind tunnel experimental investigation of sand velocity in aeolian sand transport
}

\author{
Liqiang Kang ${ }^{\mathrm{a}, \mathrm{b}, *}$, Liejin Guo ${ }^{\mathrm{b}}$, Zhengmeng Gu ${ }^{\mathrm{b}}$, Dayou Liu ${ }^{\mathrm{a}}$ \\ ${ }^{a}$ Division of Engineering Sciences, Institute of Mechanics, Chinese Academy of Sciences, Beijing 100080, China \\ ${ }^{\mathrm{b}}$ State Key Laboratory of Multiphase Flow in Power Engineering, Xi'an Jiaotong University, Xi'an 710049, China
}

Received 27 November 2006; received in revised form 27 August 2007; accepted 31 August 2007

Available online 9 September 2007

\begin{abstract}
Sand velocity in aeolian sand transport was measured using the laser Doppler technique of PDPA (Phase Doppler Particle Analyzer) in a wind tunnel. The sand velocity profile, probability distribution of particle velocity, particle velocity fluctuation and particle turbulence were analyzed in detail. The experimental results verified that the sand horizontal velocity profile can be expressed by a logarithmic function above $0.01 \mathrm{~m}$, while a deviation occurs below $0.01 \mathrm{~m}$. The mean vertical velocity of grains generally ranges from $-0.2 \mathrm{~m} / \mathrm{s}$ to $0.2 \mathrm{~m} / \mathrm{s}$, and is downward at the lower height, upward at the higher height. The probability distributions of the horizontal velocity of ascending and descending particles have a typical peak and are right-skewed at a height of $4 \mathrm{~mm}$ in the lower part of saltation layer. The vertical profile of the horizontal RMS velocity fluctuation of particles shows a single peak. The horizontal RMS velocity fluctuation of sand particles is generally larger than the vertical RMS velocity fluctuation. The RMS velocity fluctuations of grains in both horizontal and vertical directions increase with wind velocity. The particle turbulence intensity decreases with height. The present investigation is helpful in understanding the sand movement mechanism in windblown sand transport and also provides a reference for the study of blowing sand velocity.
\end{abstract}

(C) 2007 Elsevier B.V. All rights reserved.

Keywords: PDPA; Aeolian sand transport; Sand velocity; Probability distribution; Wind tunnel

\section{Introduction}

Aeolian sand transport is prevalent in natural environments, for example, deserts and sandy beaches, and also occurs on other planets such as Mars, Venus and Titan (Greeley and Iversen, 1985). Sand movement by wind occurring on a mobile sand surface is a special case of gas-solid two-phase flow. The sand movement in windblown sand transport is classified to three process-

\footnotetext{
* Corresponding author. Division of Engineering Sciences, Institute of Mechanics, Chinese Academy of Sciences, Beijing 100080, China. Tel.: +86 10 82544226; fax: +861062561284.

E-mail address: klq@sohu.com (L. Kang).
}

es: creep, saltation and suspension. Saltation is the dominant mode of blown sand movement, accounting for about $75 \%$ of the total sand flux (Bagnold, 1941). The sand movement in a saltation cloud is very complex. Sand velocity is a key factor in studying the vertical distribution of its kinetic energy, which determines the variation of abrasion intensity with height (e.g., Sharp, 1964; Suzuki and Takahashi, 1981; Greeley and Iversen, 1985; Anderson, 1986; Zou et al., 2001; Dong et al., 2004a). Hence, the sand velocity is an important parameter in the study of sand transport by wind.

In order to explore the fundamental internal mechanism in aeolian sand transport, many studies have been done using theoretical models and experiments in both 
Table 1

The setting parameters of PDPA

\begin{tabular}{ll}
\hline Item & Specification \\
\hline Transmitting lens focal length & $600 \mathrm{~mm}$ \\
Wavelength & $514.5 \mathrm{~nm}$ (green) \\
& $488 \mathrm{~nm}$ (blue) \\
Beam separation & $25 \mathrm{~mm}$ (green) \\
& $50 \mathrm{~mm}$ (blue) \\
Laser beam diameter & $1.8 \mathrm{~mm}$ (green) \\
& $1.8 \mathrm{~mm}$ (blue) \\
Fringe spacing & $12.35 \mu \mathrm{m}$ (green) \\
& $5.86 \mu \mathrm{m}$ (blue) \\
Probe volume length & 10.484 mm (green) \\
& $4.975 \mathrm{~mm}$ (blue) \\
Waist diameter & $0.218 \mathrm{~mm}$ (green) \\
& $0.207 \mathrm{~mm}$ (blue) \\
\hline
\end{tabular}

wind tunnel and field settings (e.g., Bagnold, 1941; Owen, 1964; Willetts and Rice, 1986; Ungar and Haff, 1987; Anderson and Haff, 1988, 1991; McEwan and Willetts, 1991, 1993; Greeley et al., 1996; Spies et al., 2000; Zou et al., 2001; Ni et al., 2002; Namikas, 2003; Dong et al., 2004a; McKenna Neuman, 2004; Cornelis et al., 2004; Bauer et al., 2004; Wiggs et al., 2004). The movement of grains is adapted to the near-surface wind velocity profile by a complex momentum exchange, and the trajectories of saltating grains are also dependent on many complex impact factors, such as sand size and shape, wind strength and frequency (Spies et al., 2000), sand bed topography, and environmental temperature and humidity (McKenna Neuman, 2004; Wiggs et al., 2004; Davidson-Arnott et al., 2005). The complexity of the saltation problem is apparent.

Most observations of sand motion are acquired from the high-speed photography (e.g., Willetts and Rice, 1986; Mitha et al., 1986; Willetts et al., 1991; Nalpanis et al., 1993; Rice et al., 1995, 1996; Greeley et al., 1996; Zou et al., 2001). High-speed photography can be applied to measure the velocity of individual particles. Willetts and Rice (1986) studied the rebound and ejection of sand grains after collision with the sand bed. Willetts (1991) observed the initial motion of quartz sand grains. Rice et al. $(1995,1996)$ also analyzed the collisions of saltating grains with a granular bed from

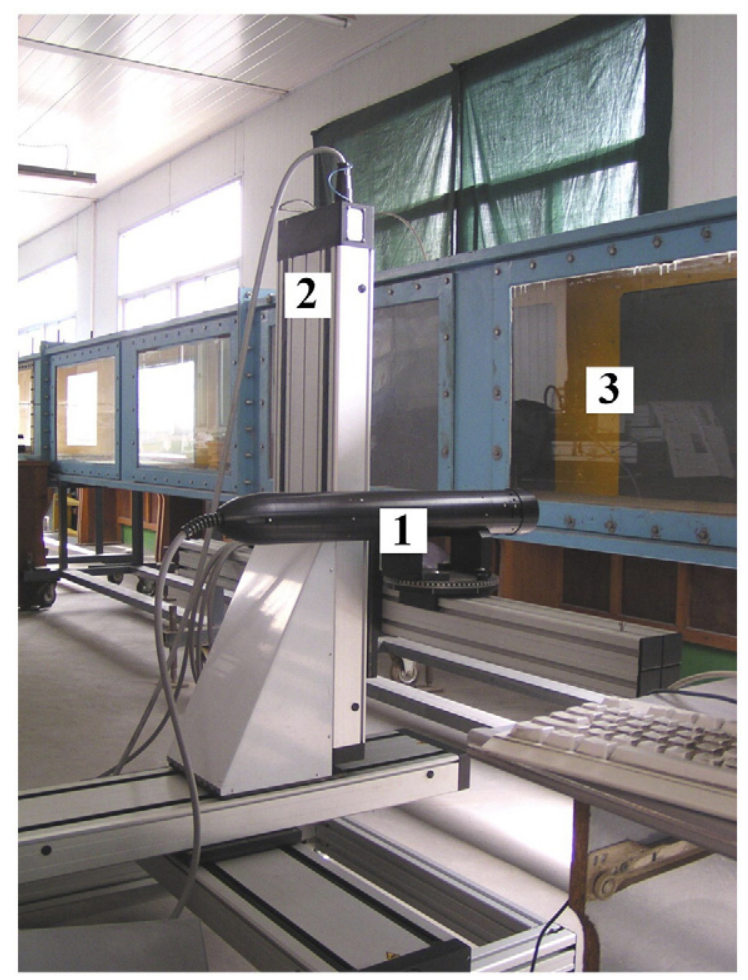

Fig. 2. The experimental layout of PDPA. (1. Transmitting probe; 2. 3-axis traverse system; 3 . Glass window of the wind tunnel).

high-speed photography. However, it is difficult to deduce the sand velocity from the photographic images at very low heights where the grains are too crowded (e.g., Zou et al., 2001). Similarly, the selection of particles is inevitably subjective, and the number of detected particles is usually very limited and insufficient for detailed analysis of particle velocity in a blowing sand cloud (Dong et al., 2002a). The analysis of particle mean velocity, probability distribution of particle velocity, particle velocity fluctuation and particle turbulence requires measuring a sufficient number of sand particles.

Zou et al. (2001) measured the particle velocity by high-speed photography in a wind tunnel, and the results show that there is a power function relation between mean velocity and the height of saltating sands, and the

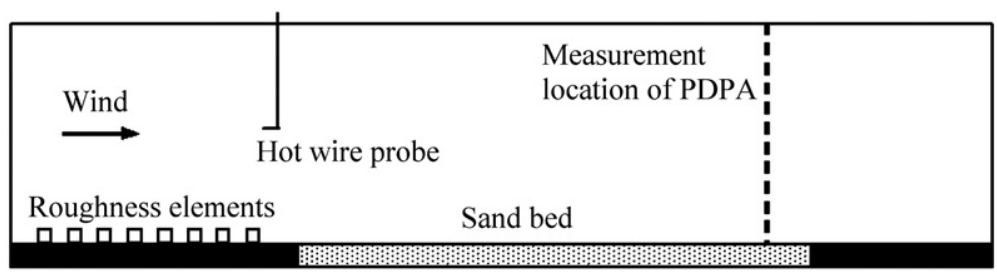

Fig. 1. Sketch of the experimental set-up in the working section of wind tunnel. 


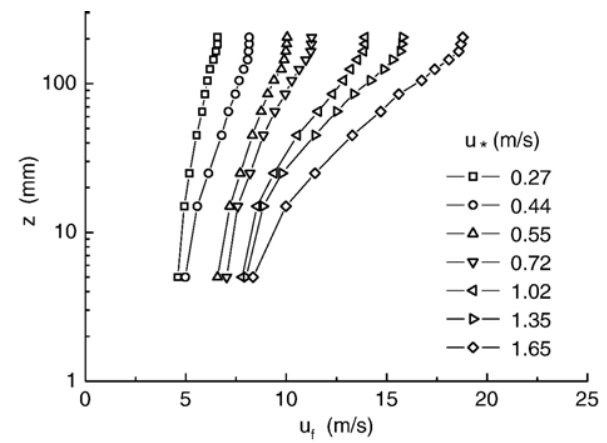

Fig. 3. Wind velocity profile in saltation.

probability distribution of sand velocity is a Pearson VII distribution pattern, but the distributions of the horizontal and vertical sand velocity were not analyzed. Greeley et al. (1996) carried out a field experiment at Pismo Beach, California, to measure the particle speed by analysis of the high-speed motion pictures of saltating grains, the results show that the velocity distributions of ascending and descending grains show a single peak. Rasmussen and Sørensen (2005) measured the grain horizontal velocity by laser Doppler method, the distributions of grain horizontal velocity show a right skew at $5 \mathrm{~mm}$ height, while at the intermediate height the variation of grain horizontal velocity is large.

Dong et al. (2002b, 2004a) first used the particle dynamic analyzer (PDA) to measure the blowing sand velocity in a wind tunnel. The PDA is also referred to as PDPA (Phase Doppler Particle Analyzer), which is a non-intrusive measurement using Doppler technique. The measurements of Dong et al. (2002b) over a gravel surface show that the particle mean horizontal velocity increases logarithmically with height. Dong et al. (2004a) gave the results that the variation of the particle mean downwind velocity over a sandy surface with

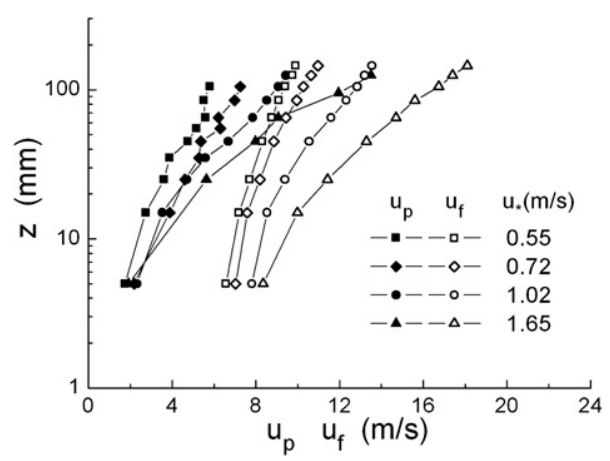

Fig. 4. Vertical profile of the wind and sand velocities in saltation. height can be expressed by a power function, but the variation of mean vertical sand velocity is complex, and the probability distribution of the downwind sand velocity complies with a Gaussian function, while that of vertical velocity is a Lorentzian function for fine particles and is complex for coarse particles.

The above investigations improved our views on blowing sand motion. However, the knowledge about sand velocity in a blowing sand cloud is still insufficient. In the present work, the characteristics of the blowing sand velocity are investigated by using a Phase Doppler Particle Analyzer (PDPA). The primary objective is to further understand the detailed information of sand velocity profile, probability distribution of particle velocity,
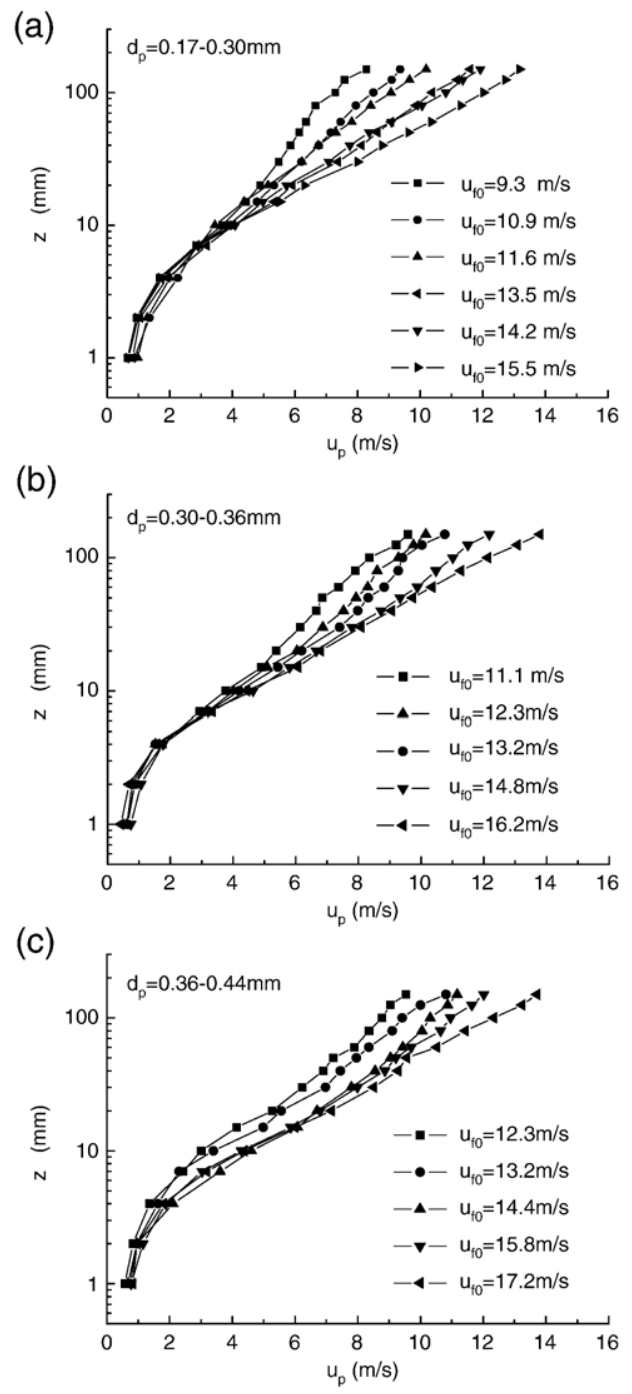

Fig. 5. Variation of the particle mean horizontal velocity $u_{p}$ with height $z$. ( $d_{p}$ is sand diameter, $\mathrm{u}_{\mathrm{f} 0}$ is the free-stream wind velocity). 
Table 2

Fitting parameters for the mean horizontal velocity of particles

\begin{tabular}{lllll}
\hline \multirow{2}{*}{$d_{p}(\mathrm{~mm})$} & $\begin{array}{l}u_{f 0} \\
(\mathrm{~m} / \mathrm{s})\end{array}$ & \multicolumn{4}{l}{$u_{p}=A+B \ln z$ for $\mathrm{z}>0.01 \mathrm{~m}$} \\
\cline { 3 - 5 } & & $\mathrm{A}$ & $\mathrm{B}$ & $R^{2}$ \\
\hline $0.17-0.30$ & 9.3 & 10.88 & 1.557 & 0.987 \\
& 10.9 & 13.15 & 2.001 & 0.998 \\
& 11.6 & 14.76 & 2.466 & 0.999 \\
& 13.5 & 16.88 & 2.766 & 0.998 \\
& 14.2 & 17.5 & 2.973 & 0.997 \\
$0.30-0.36$ & 15.5 & 19.87 & 3.426 & 0.999 \\
& 11.1 & 13.18 & 2.023 & 0.99 \\
& 12.3 & 14.35 & 2.179 & 0.992 \\
& 13.2 & 14.98 & 2.26 & 0.985 \\
$0.36-0.44$ & 14.8 & 17.42 & 2.749 & 0.997 \\
& 16.2 & 19.92 & 3.358 & 0.998 \\
& 12.3 & 14.22 & 2.352 & 0.986 \\
& 13.2 & 15.52 & 2.548 & 0.991 \\
& 14.4 & 15.91 & 2.36 & 0.989 \\
& 15.8 & 17.5 & 2.774 & 0.993 \\
& 17.2 & 20.06 & 3.363 & 0.996 \\
\hline
\end{tabular}

$d_{p}$ is sand diameter, $u_{f 0}$ is the free-stream wind velocity. $A$ and $B$ are the regression coefficients, $R^{2}$ is the correlation coefficient, $u_{p}$ is the particle mean horizontal velocity in meters per second, and $z$ is the height in meters.

particle velocity fluctuation and particle turbulence in aeolian sand transport. The work in this paper can, therefore, be considered as an interesting supplement of the work of Dong et al. (2004a).

\section{Experimental methods}

The experiment was carried out in a sand wind tunnel at the State Key Laboratory of Multiphase Flow in Power Engineering, Xi'an Jiaotong University. The wind tunnel is a blow-type non-circulating wind tunnel. The working section of wind tunnel is $12 \mathrm{~m}$ long. The cross-section of the working section is $0.4 \mathrm{~m}$ wide and $0.6 \mathrm{~m}$ high. The free-stream wind velocity in the wind tunnel can be changed continuously from 1 to $40 \mathrm{~m} / \mathrm{s}$.

The natural quartz sand is sieved into three size groups: $0.17-0.30,0.30-0.36$ and $0.36-0.44 \mathrm{~mm}$. A major characteristic of sand particles in appearance is a compact spheroidal shape with some facets, not elongated and platy. The layer of sand samples is about $4 \mathrm{~m}$ long, $0.4 \mathrm{~m}$ wide and 3-4 $\mathrm{cm}$ deep. The sand bed surface is leveled to the wind tunnel floor. According to the study of Dong et al. (2004b), a threshold fetch length in the wind tunnel is required to achieve the equilibrium saltation state. The $4 \mathrm{~m}$ length of the sand layer can reach the threshold fetch length and ensure significant development of the saltating grains cloud.

The movement of blowing grains in saltation is measured by a Phase Doppler Particle Analyzer (PDPA), a TSI apparatus. The PDPA has many advantages. It is a non-intrusive measurement using an optical technique with a high accuracy, and can give objective statistical results for many particles. The setting parameters of PDPA in the experiments are listed in Table 1.

The free-stream wind velocity is measured by a hot wire anemometer at the start of the sand bed layer. The measurement heights of sand velocity are 1, 2, 4, 7, 10, $15,20,30,40,50,60,80,100,125$ and $150 \mathrm{~mm}$ near the downwind edge of the sand layer. The sketch of the experimental set-up in the working section of wind tunnel is shown in Fig. 1.
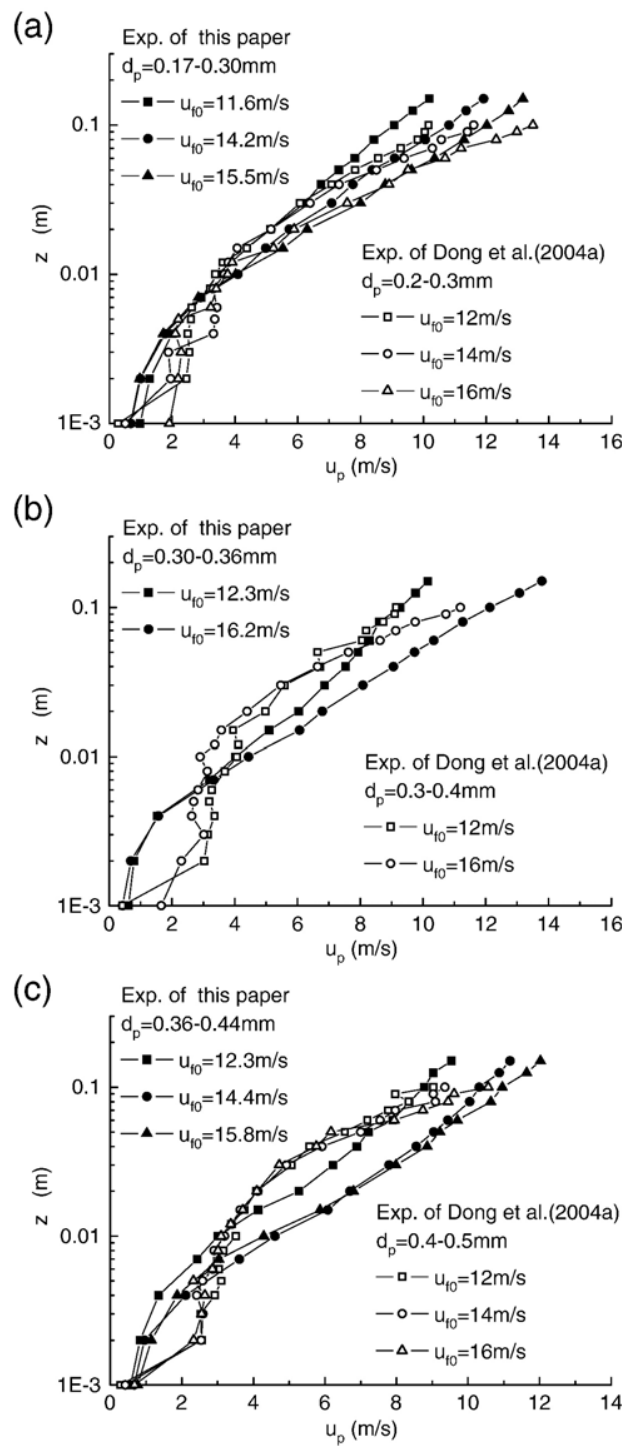

Fig. 6. Comparison of the particle mean horizontal velocity. 


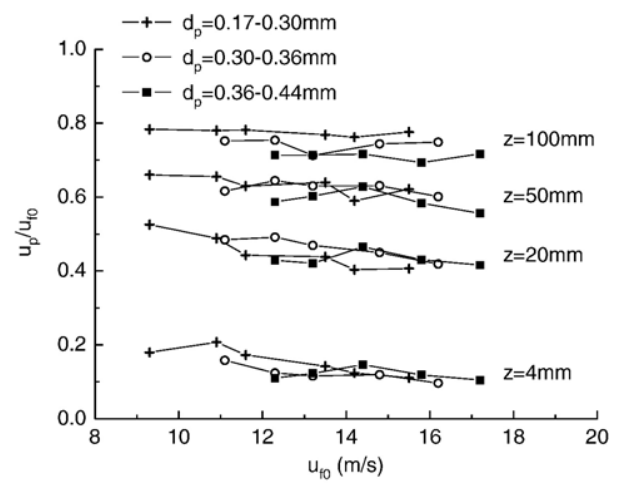

Fig. 7. Effect of sand size on the particle mean horizontal velocity.

The measurement layout of PDPA is given in Fig. 2. The 3-axis traverse system is used to precisely control the height of the velocity measurement points. The glass window of wind tunnel provides the optical access for the PDPA to produce the laser beams in the wind tunnel. The computer then records the horizontal and vertical velocity of the blowing grains.

The boundary layer thickness of the clean wind in wind tunnel is about $0.16 \mathrm{~m}$. The wind velocity profiles in saltation are measured by the hack tubes. The hack tube is calibrated with a hot wire anemometer in clean airflow. Fig. 3 shows the wind velocity profiles in saltation. In Fig. $3, u_{f}$ is the wind velocity, $u_{*}$ is the shear velocity which is deduced from the data between heights of $45 \mathrm{~mm}$ and $145 \mathrm{~mm}$, and $\mathrm{z}$ is the height. From Fig. 3, the wind boundary layer thickness during saltation at the measurement position can reach about $0.16 \mathrm{~m}$, and the wind velocity profile of $u_{*}=0.27 \mathrm{~m} / \mathrm{s}$ is just above the saltation threshold. At the middle height, the wind velocity follows a log-linear relation, while below about $20 \mathrm{~mm}$, the wind velocity deviates the log-linear relation.

\section{Experimental results and discussion}

A total of 16 experimental tests were run for particle velocity and four additional tests for both the wind and sand velocities in saltation.

\subsection{The mean horizontal velocity profile of sand cloud}

Fig. 4 shows the vertical profile of the wind and sand velocities in saltation over the $0.17-0.30 \mathrm{~mm}$ sand bed. In Fig. $4, u_{f}$ is the wind velocity, $u_{p}$ is the mean horizontal sand velocity, and $u_{*}$ is the shear velocity. At the lower height, the saltation is intensive, and all the sand velocity profiles seem to focus on about $2 \mathrm{~m} / \mathrm{s}$ at $5 \mathrm{~mm}$ height. The particle downwind velocity increases with height because the saltating grains are continually accelerated by wind.

The 16 experimental tests of the horizontal particle velocity are analyzed as follows. There are generally 500-2000 sand particles detected at the measurement point below $100 \mathrm{~mm}$ height.

Fig. 5 denotes variation of the mean horizontal particle velocity with height in log-linear plot. In Fig. $5, d_{p}$ is sand diameter, $u_{f 0}$ is the free-stream wind velocity, and $z$ is the height. From Fig. 5, the mean horizontal velocity of grains increases logarithmically with height above a height of about $0.01 \mathrm{~m}$, while a deviation occurs below the height of $0.01 \mathrm{~m}$. This variation with height of mean horizontal sand velocity is also consistent with the numerical results
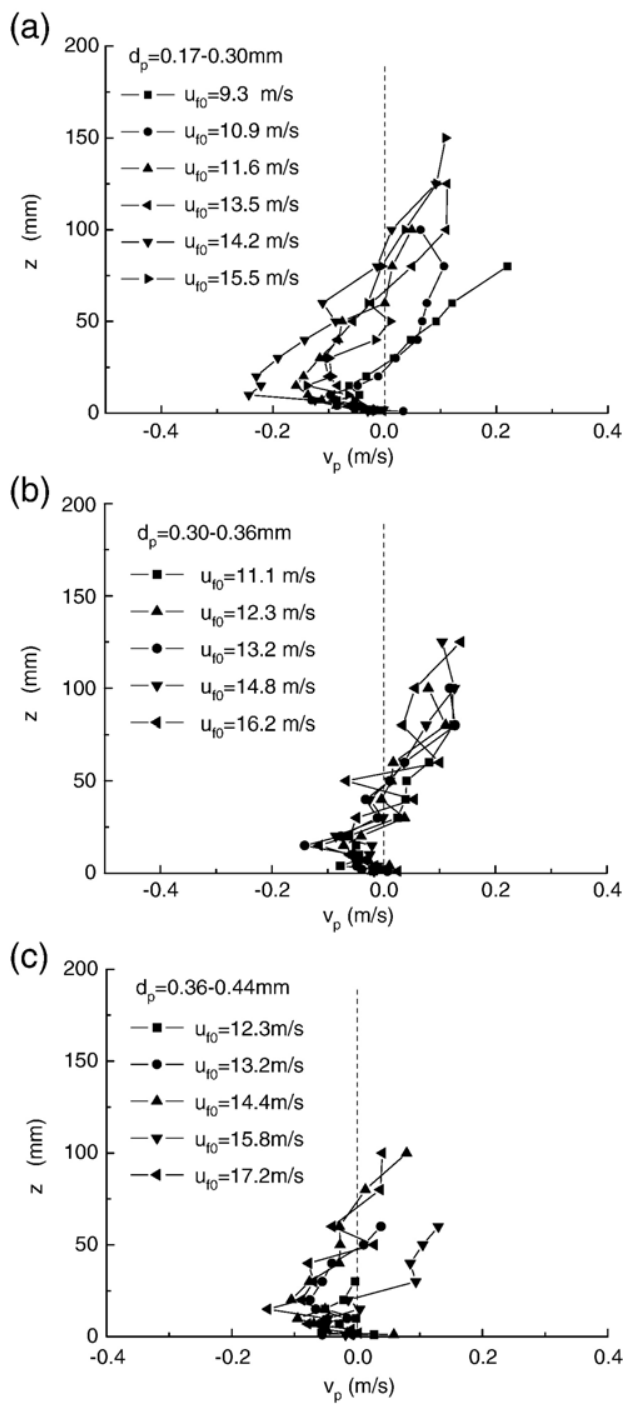

Fig. 8. Variation of the particle mean vertical velocity $v_{p}$ with height. 
(a)

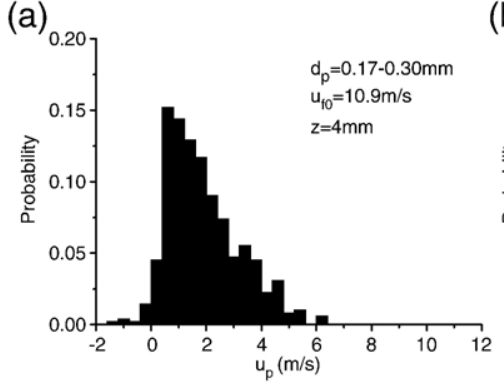

(d)

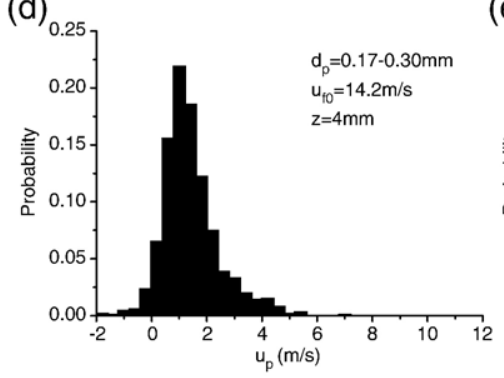

(g)

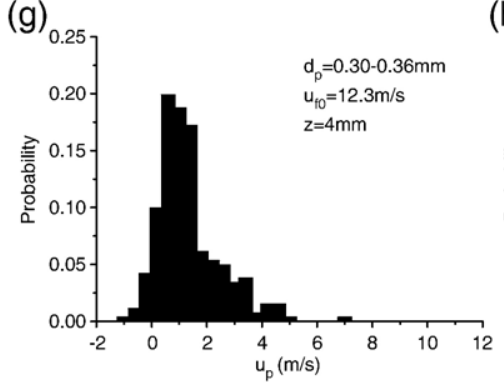

(j)

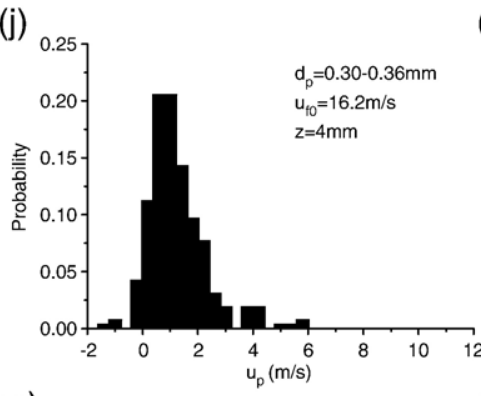

(m)

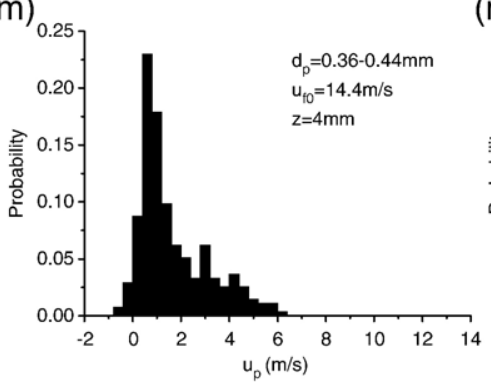

(b)

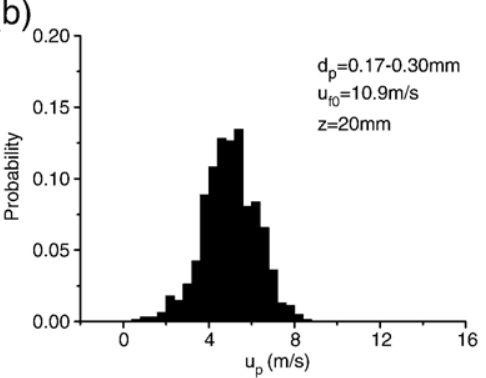

(e)

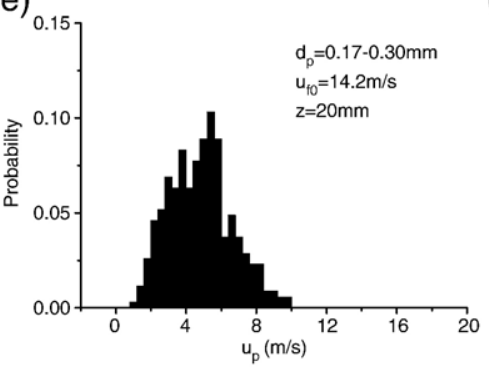

(h)

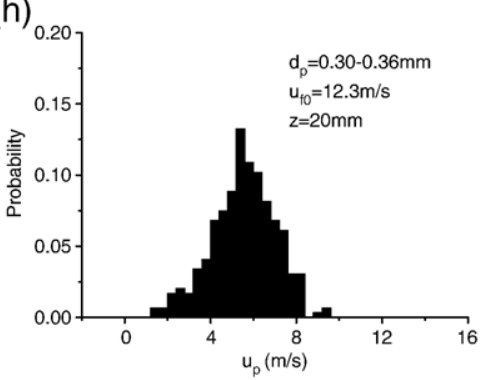

(k)

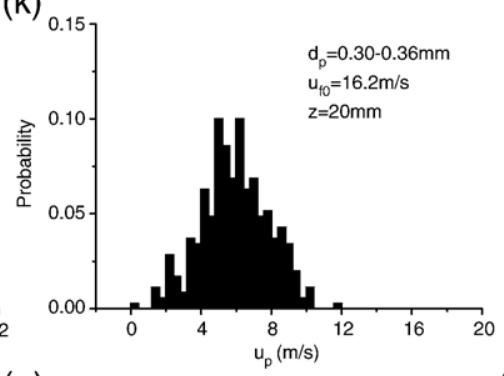

(n)

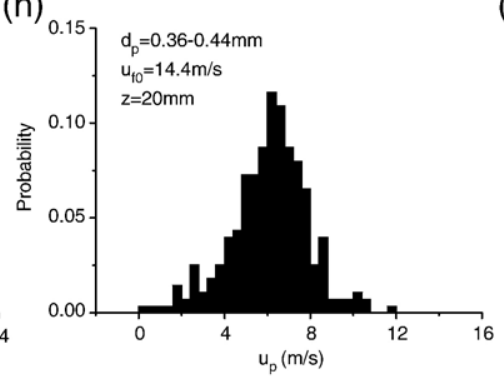

(c)

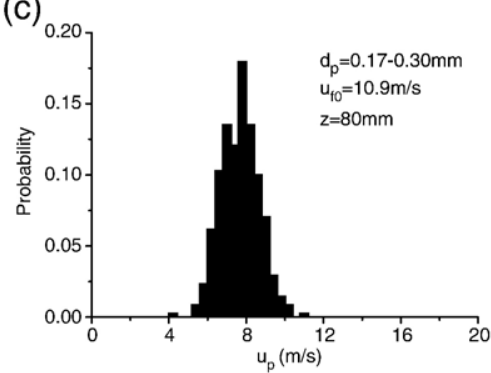

(f)

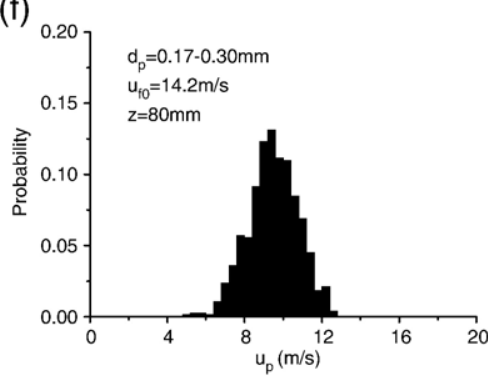

(i)

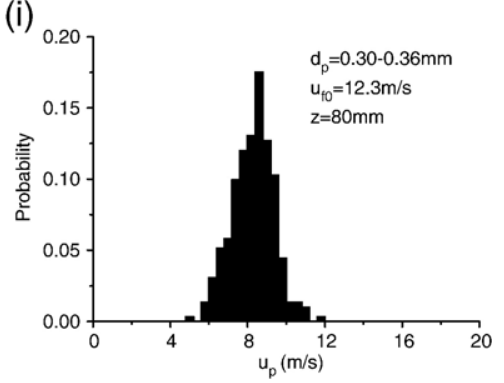

(l)

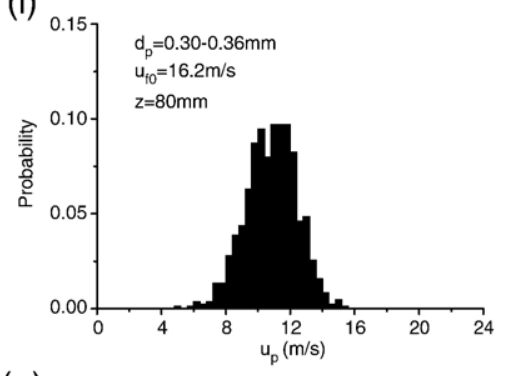

(o)

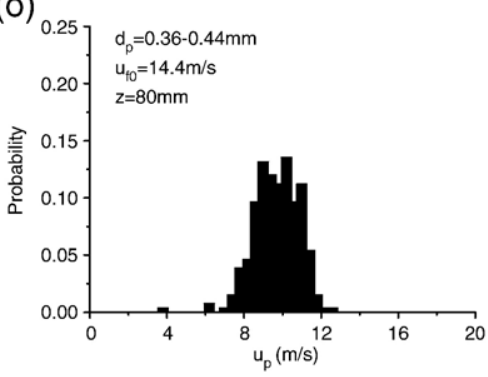

Fig. 9. Probability distribution of the horizontal velocity of ascending particles. 
(a)

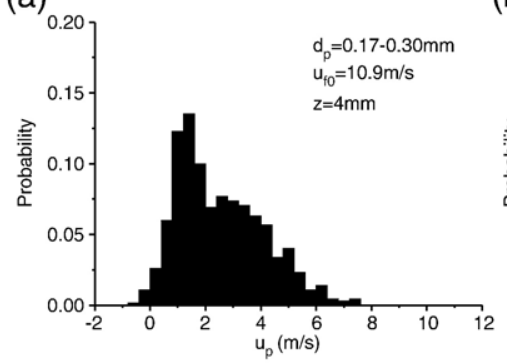

(d)

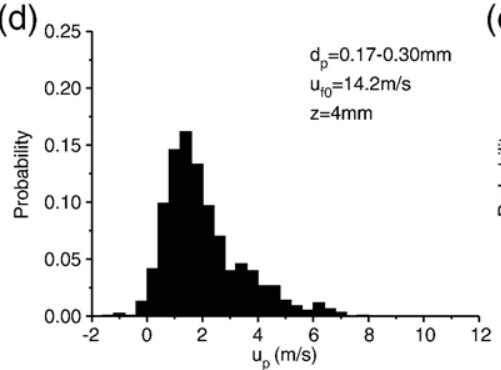

(g)
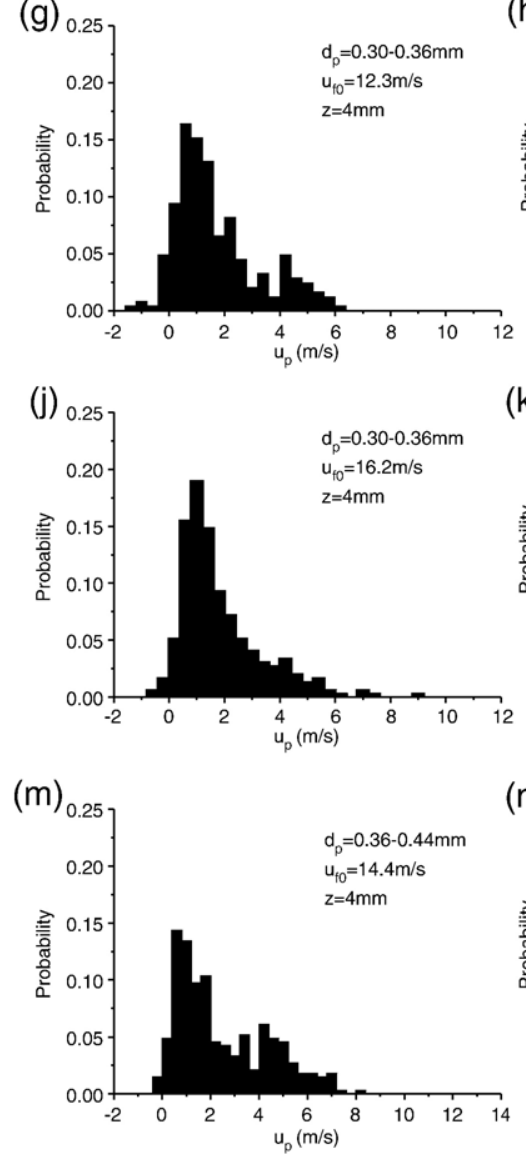

(b)

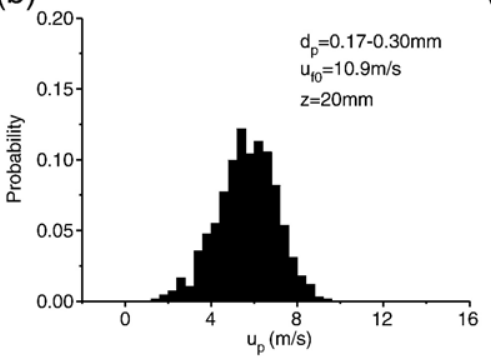

(e)

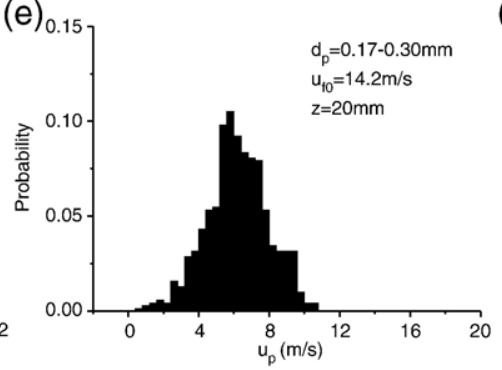

(h)
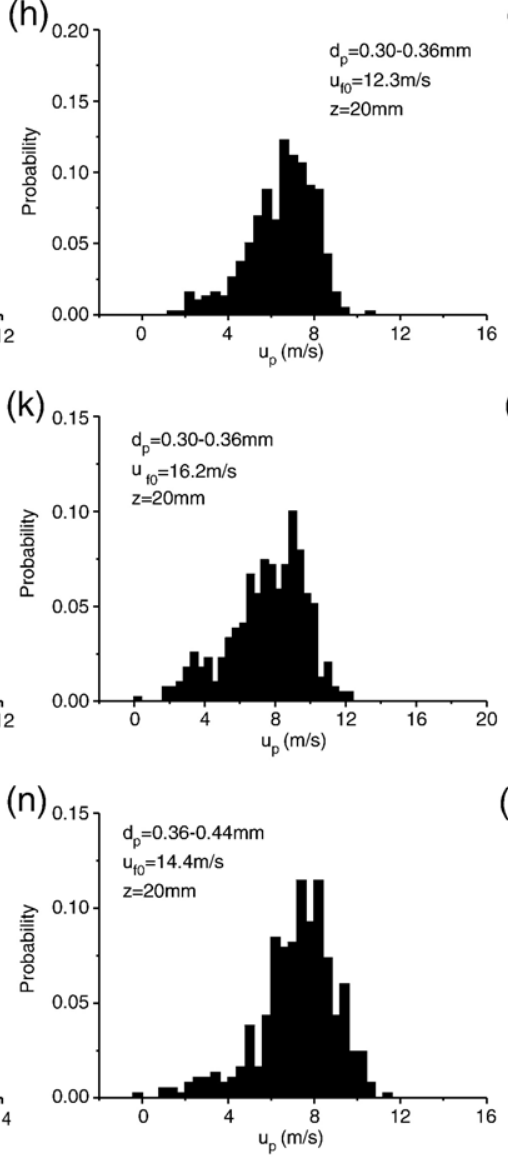

(c)

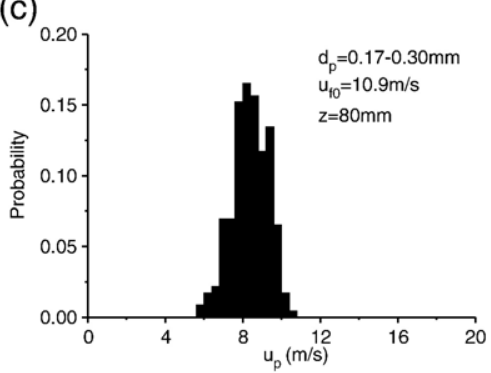

(f)

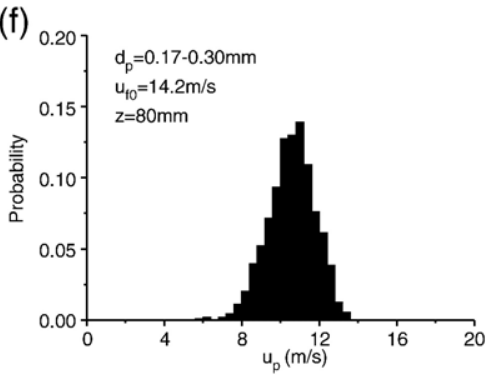

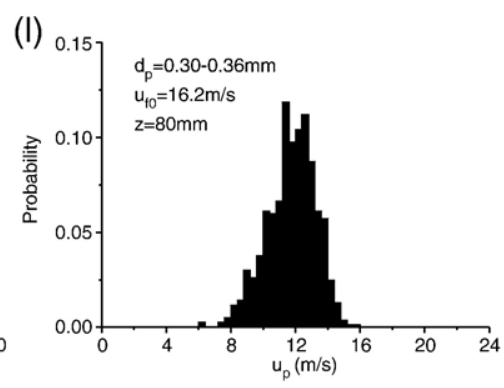

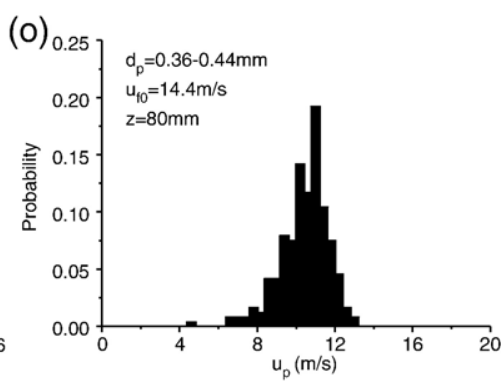

Fig. 10. Probability distribution of the horizontal velocity of descending particles.

of Kang and Guo (2006). At the higher height the wind velocity is the primary factor for the particle motion, while at the lower height the wind velocity decreases and the inter-particle collisions become stronger which can modify the particle behavior. Therefore, the deviation occurring below the height of $0.01 \mathrm{~m}$ is possibly related to 
(a)

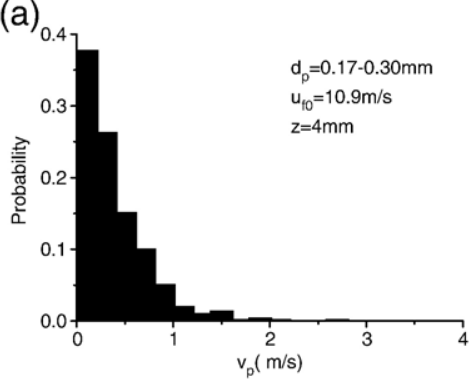

(d)

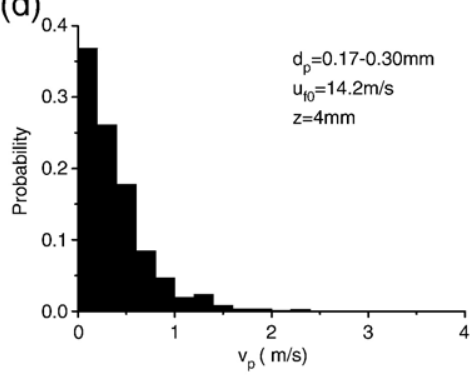

(g)

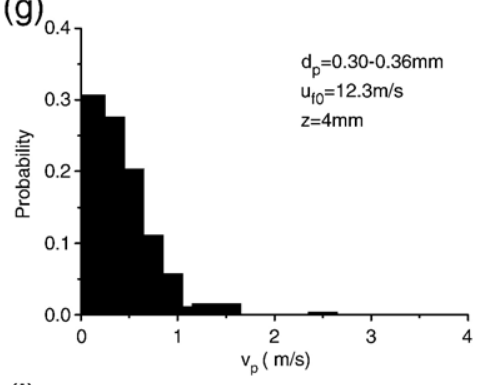

(j)

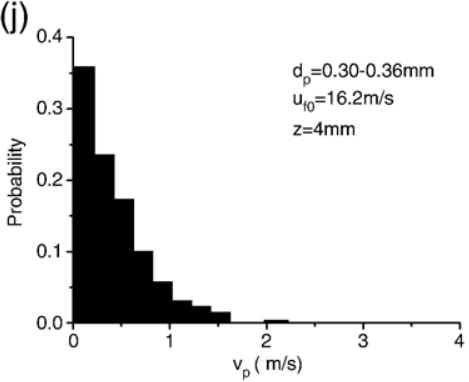

(m)

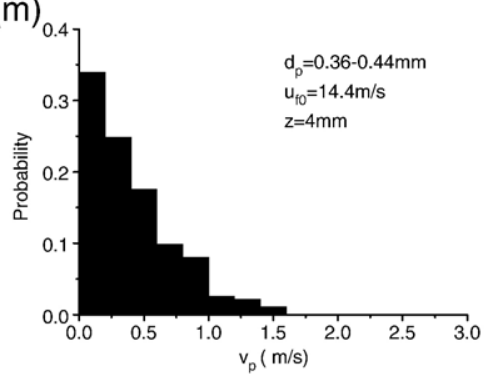

(b)

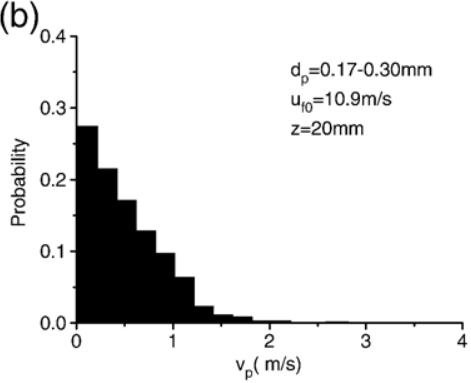

(e)

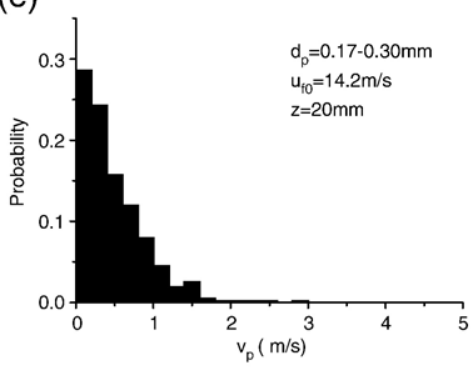

(h)

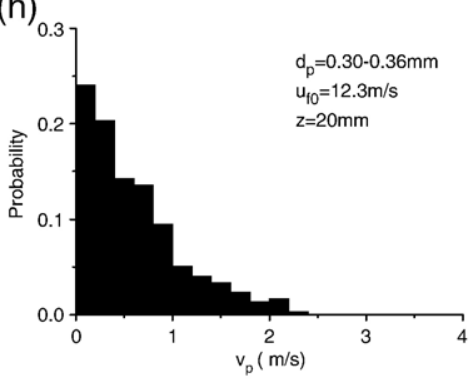

(k)

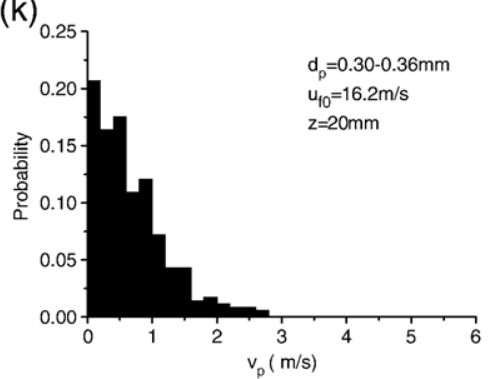

(n)

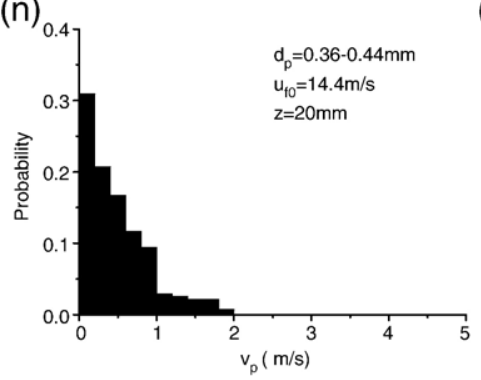

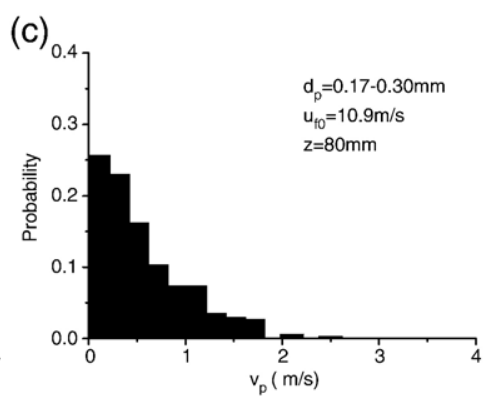

(f)

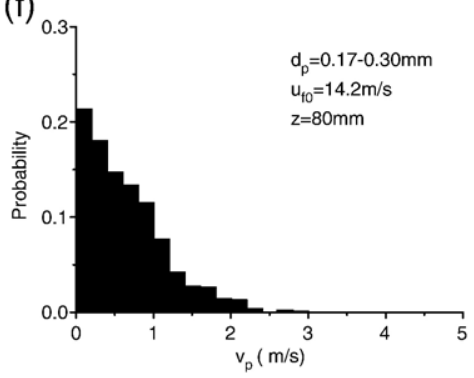

(i)

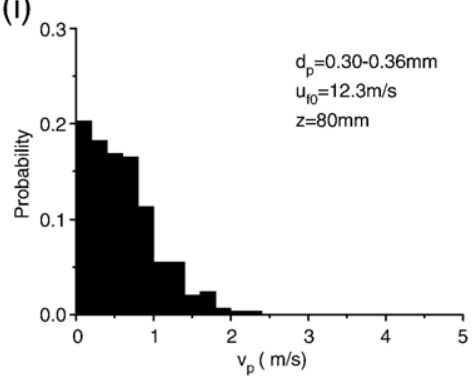

(l)

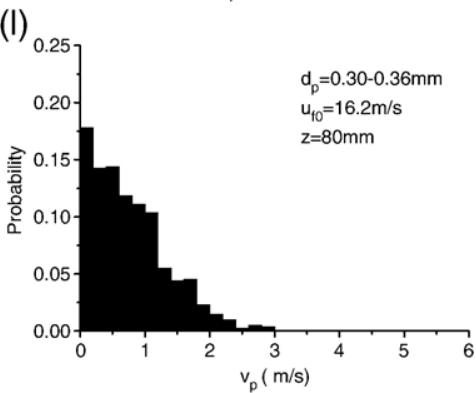

(0)

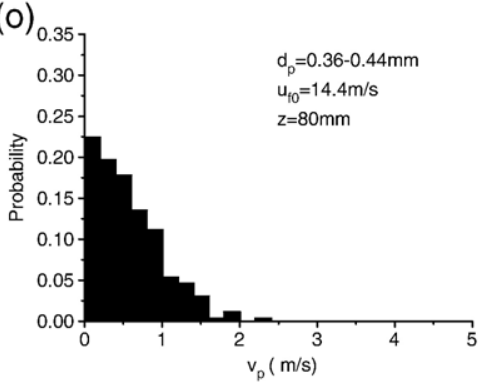

Fig. 11. Probability distribution of the vertical velocity of ascending particles.

the intensive inter-particle collisions. However, the direct measurement of inter-particle collisions is difficult and further work is needed to resolve this.
It is also seen from Fig. 5 that, except Fig. 5(c), the particle mean horizontal velocity profiles have a focus point, where the particle velocity is about $2.9 \mathrm{~m} / \mathrm{s}$ at a 
(a)

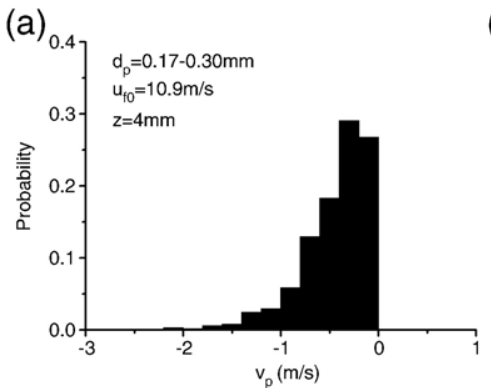

(d)
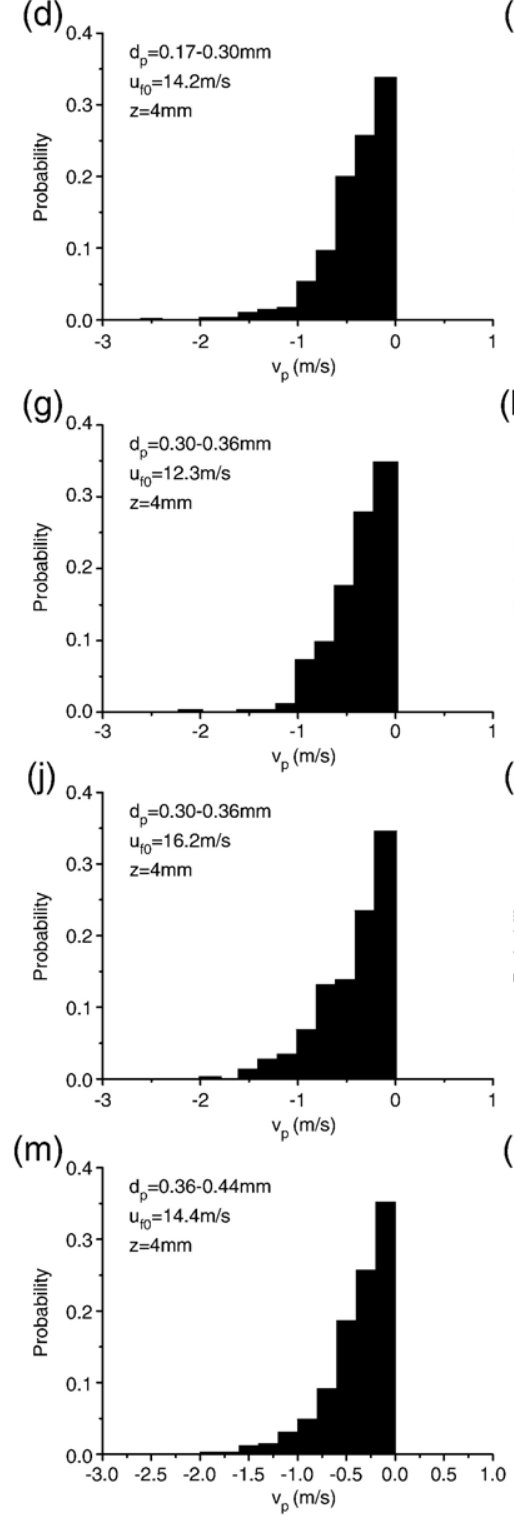

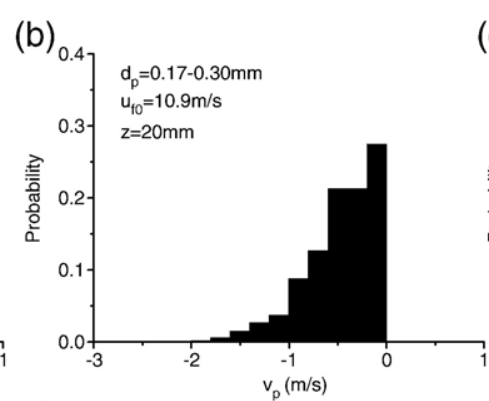

(e)
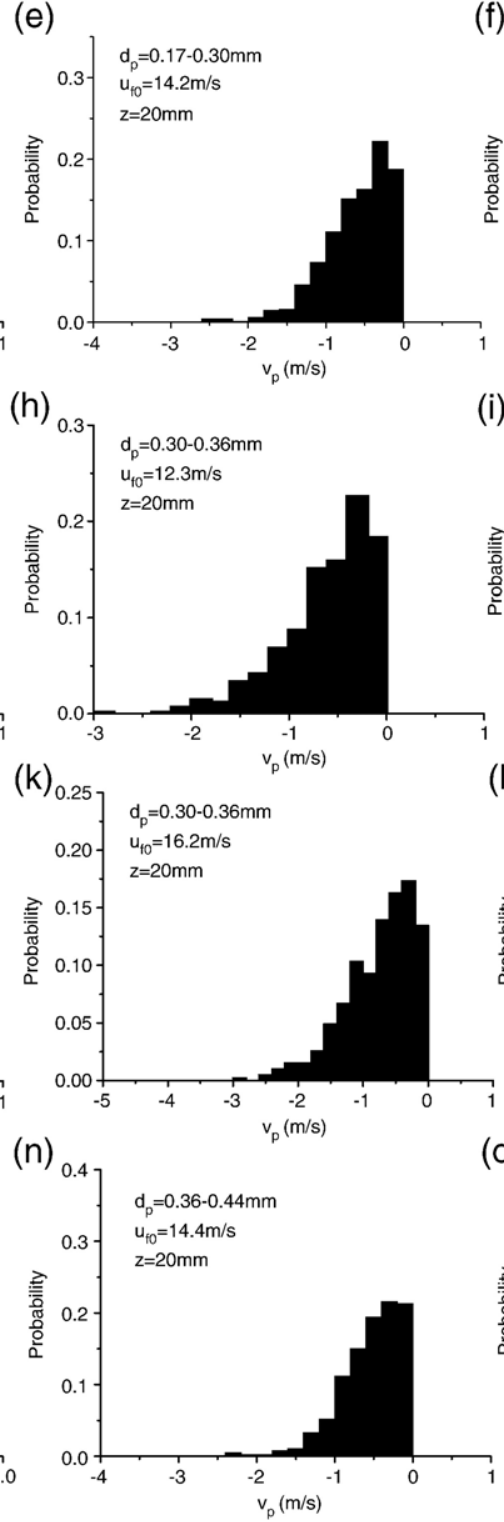
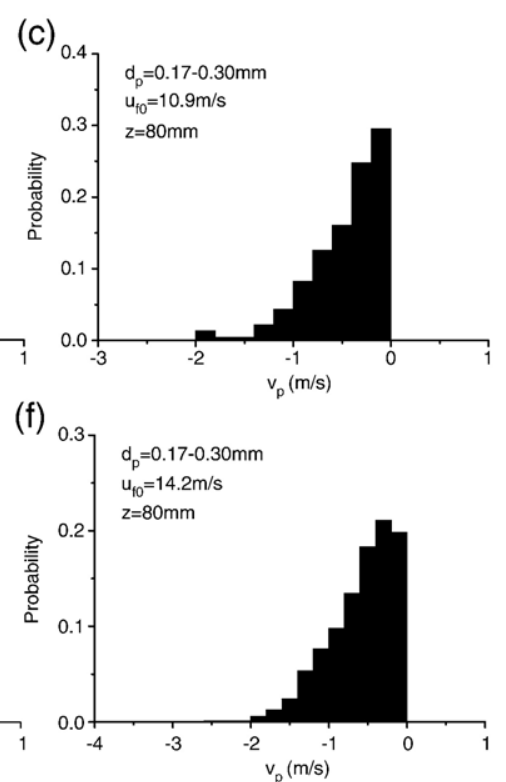

(i)

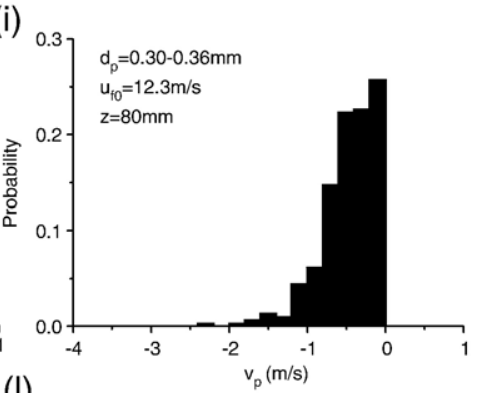

(I)
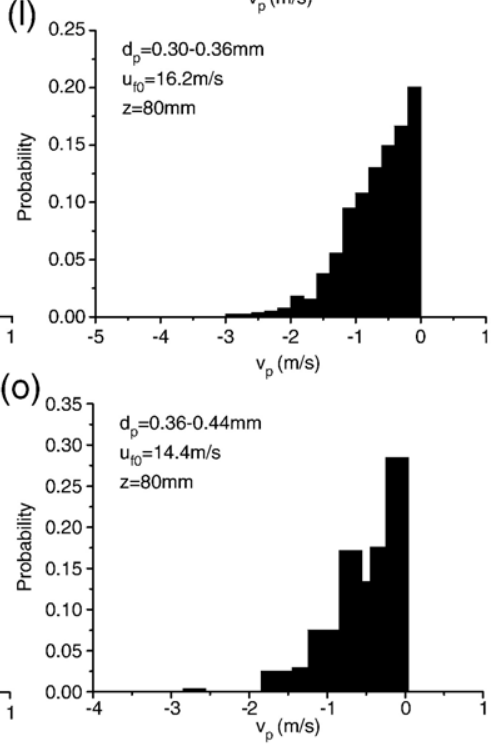

Fig. 12. Probability distribution of the vertical velocity of descending particles.

height of $7 \mathrm{~mm}$ in Fig. 5 (a), about $2.3 \mathrm{~m} / \mathrm{s}$ at $5 \mathrm{~mm}$ height in Fig. 5(b). The focus point of particle velocity profiles is similar to the Bagnold's kink in wind velocity profiles (Bagnold, 1941).
A logarithmic function is applied to describe the vertical changes of the mean downwind velocity of particles. The fitting parameters are shown in Table 2. It can be seen from Table 2 that for $z>0.01 \mathrm{~m}$, the 

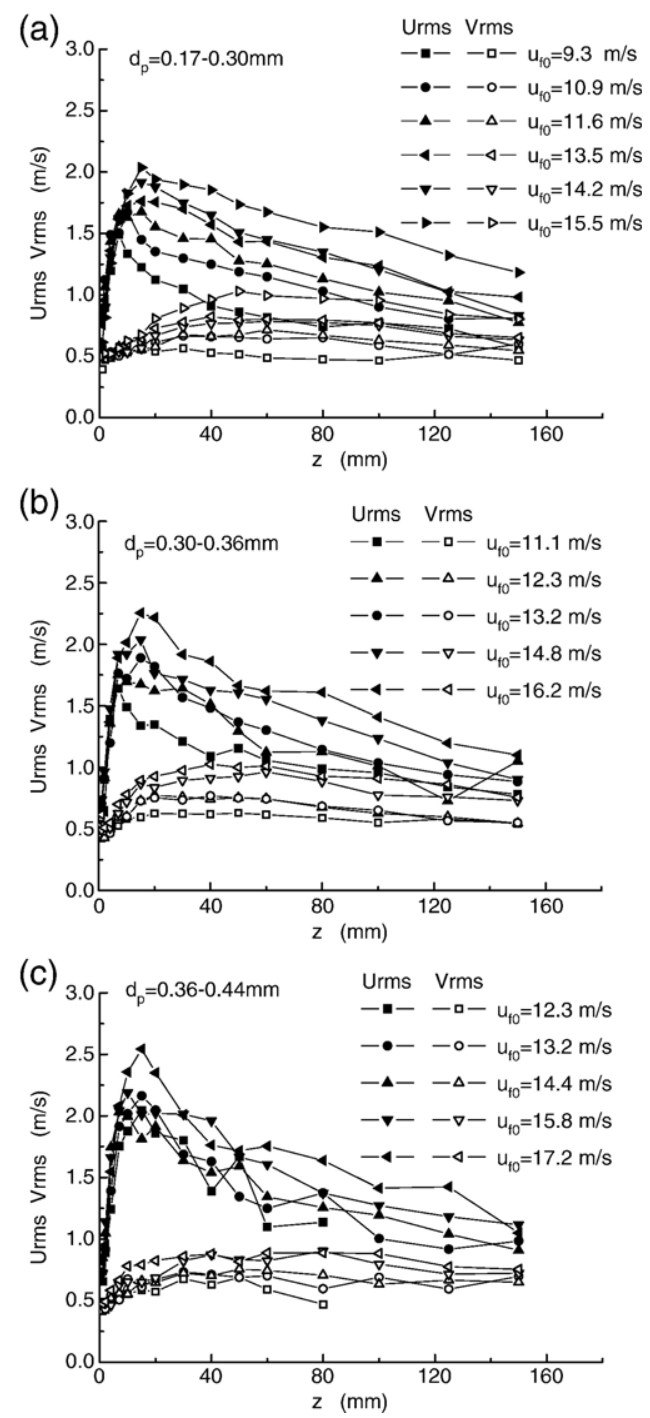

Fig. 13. Variation with height of the RMS particle velocity fluctuation.

variation of mean horizontal velocity of the particles with height can be described by a logarithmic function because all the correlations are strong $\left(R^{2}>0.98\right)$. The parameter $B$ in Table 2 can be considered as the increasing rate of mean downwind velocity of particles with height. From Table 2, the increasing rate $B$ generally increases with the free-stream wind velocity, that is to say the higher the free-stream wind velocity, the faster the sand particle velocity increases with height.

Detailed quantitative comparisons between the existing experimental data and the present results are difficult because the experimental conditions cannot be fully identical.

Dong et al. (2004a) studied the velocity of a sand cloud blowing over a sandy surface in a wind tunnel and the free-stream wind velocity was measured at the height of
$0.3 \mathrm{~m}$. In the present experiment, the free-stream wind velocity was also measured at the height of $0.3 \mathrm{~m}$, hence, direct comparison can be made, as shown in Fig. 6. It can be seen from Fig. 6 that the vertical variation of the grain velocity is similar for the results of Dong et al. (2004a) and this paper above a height of about $0.01 \mathrm{~m}$.

Fig. 7 shows the effect of grain size on the particle mean horizontal velocity. In Fig. 7, $\mathrm{u}_{\mathrm{f} 0}$ is the free-stream wind velocity, and $\mathrm{u}_{\mathrm{p}}$ is the particle mean horizontal velocity. The height of $4 \mathrm{~mm}$ can be considered to lie in the lower part of the saltation layer, the heights of $20 \mathrm{~mm}$ and $50 \mathrm{~mm}$ are in the middle part of the saltation layer, and the height of $100 \mathrm{~mm}$ lies in the upper part of the saltation layer.

It can be seen from Fig. 7 that the particle mean horizontal velocity is not dependent on the particle size
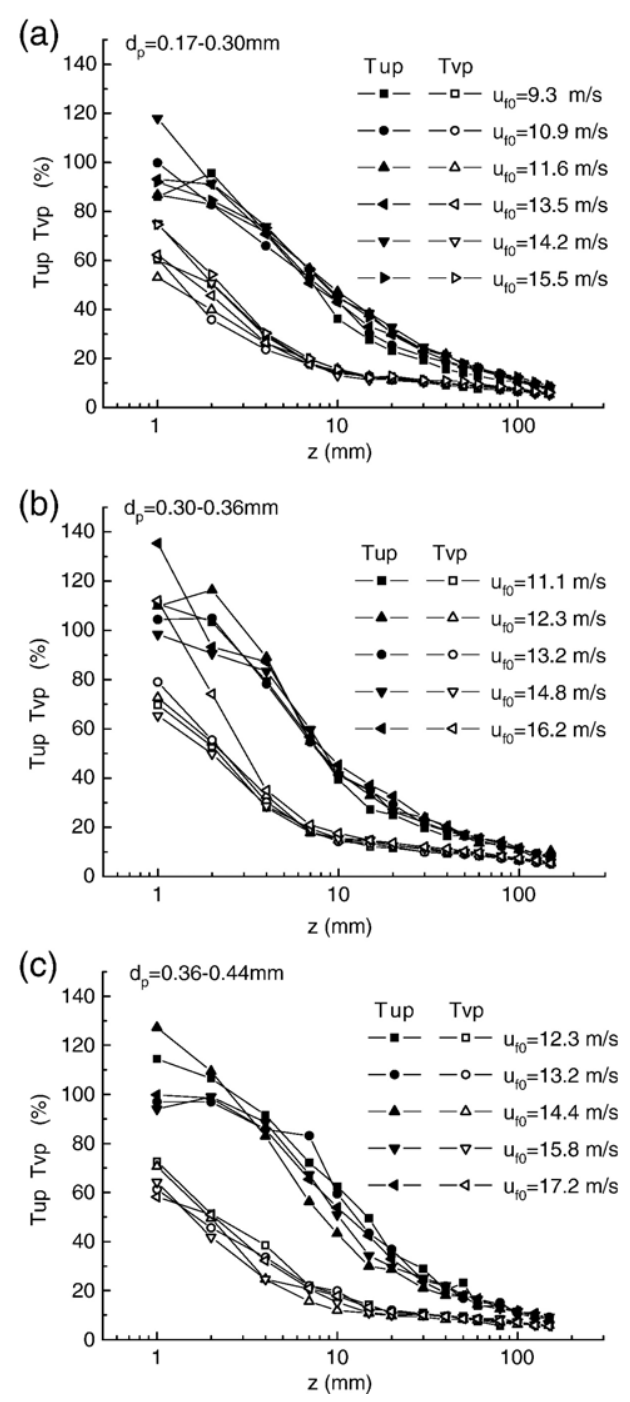

Fig. 14. Variation with height of particle turbulence in horizontal and vertical directions. 
especially below $50 \mathrm{~mm}$. In the lower part of the saltation layer, the saltation is intensive, particle motion is influenced by impact with the sand bed and inter-particle collisions in air. In the middle part of the saltation layer, particle motion is influenced by wind velocity and the inter-particle collisions in air. Here, the particle collisions probably make the particle mean velocity not obviously affected by the particle size below $50 \mathrm{~mm}$ height. The particle velocity seems to decrease with the particle size at the $100 \mathrm{~mm}$ height where the particle motion is mainly controlled by the wind.

\subsection{Variation of the particle mean vertical velocity with height}

In order to improve statistical accuracy, if the number of the validated particles is less than 1000, the corresponding data point of particle mean vertical velocity is not plotted in the figure.

Fig. 8 shows the variation with height of the mean vertical particle velocity. It can be seen that the mean vertical particle velocity is highly complicated in the vertical direction. The mean vertical velocity of grains is one or two orders less than the mean horizontal velocity, and generally ranges from -0.2 to $0.2 \mathrm{~m} / \mathrm{s}$. The varied range of the mean vertical particle velocity in this paper is consistent with that of Dong et al. (2004a).

From Fig. 8, the mean vertical velocity of grains is downward in general at the lower height, while it tends to be upward at the higher height. Again, this is basically consistent with the results of Dong et al. (2004a) above $15 \mathrm{~mm}$ height, who stated that the general mean vertical velocity of sand grains is downward between $15 \mathrm{~mm}$ and $80 \mathrm{~mm}$ heights, while it is upward at height of $z>80 \mathrm{~mm}$ and $z<15 \mathrm{~mm}$. At the higher height, the interparticle collisions are weaker, and the saltation trajectories of grains are almost similar to a parabolic curve. Hence, due to the wind drag force, the upward vertical velocity of a saltating particle will be more than the downward vertical velocity when this particle moves to the same height along the saltation trajectory, i.e., $\left|v_{p \uparrow}\right|>\mid$ $v_{p \downarrow}$, where $v_{p \uparrow}$ and $v_{p \downarrow}$ are the upward and downward vertical velocity of a saltating particle at the same height of the saltation trajectory, respectively.

In the equilibrium saltation, the mass rate of grains going up equals to the mass rate of grains going down. If it is assumed that each particle is uniform with the same mass, the number flux of upward particles is the same to that of the downward particles, as expressed by:

$N_{\text {up }}=N_{\text {down }}=N$ where $N$ is the number flux, and the subscripts $u p$ and down denote the upward and downward particles, respectively.

PDPA is a method of point measurement, hence the number of particles recorded by PDPA should be the number through a plane.

In the equilibrium saltation, the mean vertical velocity $\bar{v}_{p}$ of grains through a horizontal plane is calculated by

$\bar{v}_{p}=\frac{\sum_{i=1}^{N_{\text {up }}}\left|v_{p \uparrow, i}\right|-\sum_{i=1}^{N_{\text {down }}}\left|v_{p \downarrow, i}\right|}{N_{\text {up }}+N_{\text {down }}}=\frac{\sum_{i=1}^{N}\left(\left|v_{p \uparrow, i}\right|-\left|v_{p \downarrow, i}\right|\right)}{2 N}>0$

Therefore, from the above Eq. (2), at the higher height, the particle mean vertical velocity through a horizontal plane is upward.

At the lower height, the particle collisions are stronger, the vertical sand velocity is affected by the particle-bed collision and the inter-particle collisions in mid-air. The trajectories of saltating grains are complicated. The mean vertical velocity of grains being downward at the lower height is related to these inter-particle collisions. However, informed explanations cannot be given because the inter-particle collisions are very complex.

\subsection{Probability distribution of the horizontal and vertical velocities for ascending and descending particles}

In windblown sand movement, the velocity of each sand particle passed a fixed point is different. Hence, the velocity of a large number of sand grains at a given point can show a probability distribution pattern. In the following, the probability distributions of particle velocity are analyzed for ascending and descending particles, respectively. Three heights are selected, i.e., 4, 20 and $80 \mathrm{~mm}$, which lie in the different part of the saltation layer.

Figs. 9 and 10 show the probability distribution of the horizontal velocity of ascending and descending particles, respectively. It can be seen from Figs. 9 and 10 that the shapes of these histograms have a typical peak. Greeley et al. (1996) gave a result from the high-speed motion pictures that the velocity distributions of ascending and descending grains show a single peak, but the horizontal and vertical velocities were not analyzed.

At the height of $4 \mathrm{~mm}$ in the lower part of the saltation layer, the probability distributions of the horizontal velocity of ascending and descending particles are rightskewed. These horizontal velocity distributions are similar to the findings of Rasmussen and Sørensen (2005), in which the distributions of grain horizontal velocity are right-skewed at $5 \mathrm{~mm}$ height. The explanation is described by Rasmussen and Sørensen (2005) as "during the splash maybe only a single grain may receive 
a large part of the forward momentum of the impinging grain while several grains will receive some momentum and thus make low, short jumps".

At the middle height $(20 \mathrm{~mm})$, the shapes of horizontal velocity distributions are relatively complex, some distributions seem to be left-skewed (Fig. 9(h), Fig. 10 (h), (k), (n)). The left skew shapes may be caused by some short jump grains from the splash process, which can reach a height of $20 \mathrm{~mm}$ with lower horizontal velocity. The variation of horizontal velocity is large at the $4 \mathrm{~mm}$ and $20 \mathrm{~mm}$ heights.

At the upper height $(80 \mathrm{~mm})$, the skewness of horizontal velocity distributions seems to be relatively small.

It is also found from Figs. 9 and 10 that at the same height, the mean horizontal velocity of descending particles is larger than that of ascending grains, because the descending grains are accelerated by wind for a longer time in comparison with the ascending grains.

From Figs. 9 and 10, the movement of some particles is in the opposite direction to the wind because a negative value of the horizontal velocity of grains at height of $4 \mathrm{~mm}$ appears. The backward movement of grains is mainly related to the splash process and mid-air collisions which can bring a favorable condition for the generation of the backward grains.

Figs. 11 and 12 illustrate the probability distribution of the vertical velocity of ascending and descending particles, respectively. The vertical velocity probability of ascending particles decreases generally with increasing vertical velocity, while the vertical velocity probability of descending particles increases with the vertical velocity (note that the vertical velocity of descending particles is negative).

At the $4 \mathrm{~mm}$ height, the vertical velocity distribution of ascending and descending particles generally follows an exponential function. While at the $80 \mathrm{~mm}$ height, the vertical velocity distribution of ascending and descending particles seems to be a linear relation. The underlying mechanism of these vertical velocity distributions is still not fully understood.

\subsection{Particle velocity fluctuation}

Fig. 13 gives the variation with height of the rootmean-square (RMS) particle velocity fluctuation in horizontal and vertical directions. In Fig. 13, $U_{\text {rms }}$ and $V_{\text {rms }}$ are the horizontal and vertical RMS particle velocity fluctuations, respectively. It can be seen that these profiles have a similar shape under different free-stream wind velocities. The vertical profile of the RMS velocity fluctuation of grains in the horizontal direction shows a typical peak which appears at a height of about 5-20 mm, while the vertical RMS velocity fluctuation increases generally with height at the lower height $(z<30 \mathrm{~mm})$ and has a slight decrease with height in most cases at the higher height $(z>50 \mathrm{~mm})$. The horizontal RMS velocity fluctuation of grains is generally larger than the vertical RMS velocity fluctuation at the same height. The RMS velocity fluctuations of grains in both horizontal and vertical directions increase with wind velocity.

\subsection{Particle turbulence}

Particle turbulence reflects the relative intensity of the velocity fluctuation of sand particles. In this paper, the particle turbulence is defined as follows:

$$
\begin{aligned}
& T_{\mathrm{up}}=\frac{1}{u_{\mathrm{pm}}} \sqrt{\frac{1}{N} \sum_{i=1}^{N}\left(u_{p, i}-u_{\mathrm{pm}}\right)^{2}} \\
& T_{\mathrm{vp}}=\frac{1}{u_{\mathrm{pm}}} \sqrt{\frac{1}{N} \sum_{i=1}^{N}\left(v_{p, i}-v_{\mathrm{pm}}\right)^{2}}
\end{aligned}
$$

where $T_{\mathrm{up}}$ and $T_{\mathrm{vp}}$ are the horizontal and vertical particle turbulence intensity, respectively. $u_{\mathrm{pm}}$ and $v_{\mathrm{pm}}$ are the mean horizontal and vertical velocities of grains, respectively. $u_{p, i}$ and $v_{p, i}$ are the horizontal and vertical velocities of particle $i$, respectively. $N$ is the number of the statistical particles.

Fig. 14 shows the variation of the particle turbulence in horizontal and vertical directions with height. The particle turbulence in the horizontal and vertical directions decreases generally with height at all freestream wind velocities. The maximum of the horizontal and vertical particle turbulence intensity occurs near the ground surface. The vertical profile of the horizontal particle turbulence intensity in this paper is similar to the experimental results of Dong et al. (2004a).

From Figs. 13 and 14, the deviation between the horizontal and vertical particle velocity fluctuation at the lower height is larger than that at the higher height, that is to say the anisotropy of particle velocity fluctuation is intensive at the lower height.

\section{Conclusions}

Particle velocity in a blowing sand cloud is analyzed by using the measurement technology of PDPA in a wind tunnel. Some features are revealed as follows:

(1) The sand horizontal velocity profile can be expressed by a logarithmic function above $0.01 \mathrm{~m}$, while a deviation occurs below $0.01 \mathrm{~m}$. 
(2) The mean vertical velocity of grains is downward in general at the lower height (below about $25 \mathrm{~mm}$ ), while upward at the higher height (above about $60 \mathrm{~mm}$ ).

(3) The probability distributions of the horizontal velocity of ascending and descending particles have a typical peak and are right-skewed at a height of $4 \mathrm{~mm}$ in the lower part of saltation layer.

(4) The vertical profile of the horizontal RMS velocity fluctuation of grains shows a single peak. The RMS velocity fluctuation of particles in the horizontal direction is more than that in the vertical direction. The RMS velocity fluctuations of grains in both horizontal and vertical directions increase with wind velocity.

(5) The particle turbulence in the horizontal and vertical directions decreases generally with height.

\section{Acknowledgements}

This work is supported by National Natural Science Foundation of China (Grant No. 10532030) and Major State Basic Research Development Program of China (Grant No. G2000048702).

\section{References}

Anderson, R.S., 1986. Erosion profiles due to particles entrained by wind: application of an eolian sediment-transport model. Geological Society of America Bulletin 97, 1270-1278.

Anderson, R.S., Haff, P.K., 1988. Simulation of eolian saltation. Science 241, 820-823.

Anderson, R.S., Haff, P.K., 1991. Wind modification and bed response during saltation of sand in air. Acta Mechanica (suppl.1), 21-51.

Bagnold, R.A., 1941. The Physics of Blown Sand and Desert Dunes. Methuen, London.

Bauer, B.O., Houser, C.A., Nickling, W.G., 2004. Analysis of velocity profile measurements from wind-tunnel experiments with saltation. Geomorphology 59, 81-98.

Cornelis, W.M., Gabriels, D., Hartmann, R., 2004. A parameterization for the threshold shear velocity to initiate deflation of dry and wet sediment. Geomorphology 59, 43-51.

Davidson-Arnott, R.G.D., MacQuarrie, K., Aagaard, T., 2005. The effect of wind gusts, moisture content and fetch length on sand transport on a beach. Geomorphology 68, 115-129.

Dong, Z.B., Liu, X.P., Li, F., Wang, H.T., Zhao, A.G., 2002a. Impactentrainment relationship in a saltating cloud. Earth Surface Processes and Landforms 27, 641-658.

Dong, Z.B., Liu, X.P., Wang, X.M., Li, F., Zhao, A.G., 2004a. Experimental investigation of the velocity of a sand cloud blowing over a sandy surface. Earth Surface Processes and Landforms 29, 343-358.

Dong, Z.B., Wang, H.T., Liu, X.P., Li, F., Zhao, A.G., 2002b. Velocity profile of a sand cloud blowing over a gravel surface. Geomorphology $45,277-289$.
Dong, Z.B., Wang, H.T., Liu, X.P., Wang, X.M., 2004b. The blown sand flux over a sandy surface: a wind tunnel investigation on the fetch effect. Geomorphology 57, 117-127.

Greeley, R., Blumberg, D.G., Williams, S.H., 1996. Field measurements of the flux and speed of wind-blown sand. Sedimentology $43,41-52$.

Greeley, R., Iversen, J.D., 1985. Wind as a geological process on Earth, Mars, Venus and Titan. Cambridge Univ. Press, Cambridge.

Kang, L.Q., Guo, L.J., 2006. Eulerian-Lagrangian simulation of aeolian sand transport. Powder Technology 162, 111-120.

McEwan, I.K., Willetts, B.B., 1991. Numerical model of the saltation cloud. Acta Mechanica (suppl.1), 53-66.

McEwan, I.K., Willetts, B.B., 1993. Adaptation of the near-surface wind to the development of sand transport. Journal of Fluid Mechanics 252, 99-105.

McKenna Neuman, C., 2004. Effects of temperature and humidity upon the transport of sedimentary particles by wind. Sedimentology 51 , $1-17$.

Mitha, S., Tran, M.Q., Werner, B.T., Haff, P.K., 1986. The grain-bed impact process in aeolian saltation. Acta Mechanica 63, 267-278.

Nalpanis, P., Hunt, J.C.R., Barrett, C.F., 1993. Saltating particles over flat beds. Journal of Fluid Mechanics 251, 661-685.

Namikas, S.L., 2003. Field measurement and numerical modelling of aeolian mass flux distributions on a sandy beach. Sedimentology 50, 303-326.

Ni, J.R., Li, Z.S., Mendoza, C., 2002. Vertical profiles of aeolian sand mass flux. Geomorphology 49, 205-218.

Owen, P.R., 1964. Saltation of uniform grains in air. Journal of Fluid Mechanics 20, 225-242.

Rasmussen, K.R., Sørensen, M., 2005. Dynamics of particles in aeolian saltation. Powders and Grains 2005, vol. 2. Balkema A.A., Rotterdam, pp. 967-972.

Rice, M.A., Willetts, B.B., McEwan, I.K., 1995. An experimental study of multiple grain-size ejecta produced by collisions of saltating grains with a flat bed. Sedimentology 42, 695-706.

Rice, M.A., Willetts, B.B., McEwan, I.K., 1996. Observation of collisions of saltating grains with a granular bed from high-speed cine-film. Sedimentology 43, 21-31.

Sharp, R.P., 1964. Wind-driven sand in Coachella Valley, California. Geological Society of America Bulletin 75, 785-804.

Spies, P.-J., McEwan, I.K., Butterfield, G.R., 2000. One-dimentional transitional behaviour in saltation. Earth Surface Processes and Landforms 25, 505-518.

Suzuki, T., Takahashi, K., 1981. An experimental study of wind abrasion. Journal of Geology 89, 23-36.

Ungar, J.E., Haff, P.K., 1987. Steady state saltation in air. Sedimentology 34, 289-299.

Wiggs, G.F.S., Baird, A.J., Atherton, R.J., 2004. The dynamic effects of moisture on the entrainment and transport of sand by wind. Geomorphology 59, 13-30.

Willetts, B.B., McEwan, I.K., Rice, M.A., 1991. Initiation of motion of quartz sand grains. Acta Mechanica (suppl.1), 123-134.

Willetts, B.B., Rice, M.A., 1986. Collisions in aeolian saltation. Acta Mechanica 63, 255-265.

Zou, X.Y., Wang, Z.L., Hao, Q.Z., Zhang, C.L., Liu, Y.Z., Dong, G.R., 2001. The distribution of velocity and energy of saltating sand grains in a wind tunnel. Geomorphology 36, 155-165. 